\title{
THE BIOLOGICAL POINT OF VIEW IN PSYCHOLOGY AND PSYCHIATRY
}

\author{
BY E. STANLEY ABBOT
}

Mclean Hospital, Waverley, Mass.

The advantage and necessity of taking the biological point of view in psychology and psychiatry have been urged in recent years by psychologists and especially by Dr. Adolf Meyer and other psychiatrists. To this necessity the writer heartily agrees. For this point of view makes the study of these subjects objective and as free as possible from metaphysical bias and a prioristic theories. It also sets more definite and workable problems, and establishes a criterion for evaluating both old and new theories and conceptions.

Because this point of view seems to the writer to have been imperfectly conceived and inadequately applied, and because it and its implications have been nowhere fully set forth, this attempt to supply the deficiency is made.

If we regard biology only as the science of matter in the living state, it is limited to studies of structure and its physiological activities; but if we take the broader, and in the writer's belief truer meaning, biology is the science of living things. This includes not only studies of structure but of all the activities of the biological unit, including its conduct or behavior. Jennings's studies of the behavior of the lower organisms belong to biology just as much as do Loeb's physiological studies.

The fundamental differences between non-living and living things are that the latter by internal activities make themselves out of the materials of their environment, and reproduce their kind. In a very limited sense even the non-living thing may be said to adapt itself to the environment, in that it reacts by its own inertia to the forces that act upon it, but not by any internal self-directive activities of its own. In the world of living things there is the same reaction of inertia 
as in non-living things, but in addition there are internal activities, some of which are of a self-directive nature.

In the vegetable world these internal activities are little, if any, modified by the plant itself, though some botanists hold that root-caps and vine tendrils, for example, exercise a direction of the plant activities which is not wholly explained by the various tropisms to which the plant is subject.

But in the animal series, as we ascend the evolutionary scale, the self-directive internal activities assume a progressively greater prominence in the reactions of the individual to its environment. The life of the individual biological unit consists in the continuous adaptation of itself to its environment as well as it can. That is its job in life. If it absolutely stops reacting by internal activities, it dies. If it does not react as well as it can, it succumbs to external agencies or does less well than its neighbor. (Even we human beings try to justify ourselves and others when we have done less well than we might, and we rarely intentionally do less well than we know at the moment of acting, though often afterwards we see how we might have done better.) This self-adaptation is minimal in the resting stage of spores and seeds, and in the higher animals in hibernation and in sleep, and is maximal in the wide-awake activities of the higher animals, especially man.

We may say then that from the biological point of view man is a biological unit reacting as well as he can to his environment by means of internal self-directive activities which determine his outward acts. Many of these internal activities are physiological, but most of these which result in his external behavior or conduct are psychological. All of his activities are directed to the great end of his best selfadjustment to his whole environment, though lesser or nearer and more concrete ends are usually more immediately prominent to the individual. That is, he usually reacts to the immediate present situation without much thought of his reaction being an integral and essential part of a large adjustment to life, $i$. e., to his whole environment, including his whole past, present and future situations, experiences and reactions. 
The psychical activities of any biological unit, then, are links in the chain of internal reactions by which the unit adjusts itself or reacts to the forces which act on it and the situations in which it finds itself. Each link is a reaction, effect of preceding links, cause of succeeding ones. In psychology then we not only have to study the special psychic act or type of acts as a separate entity or process, but we should always study also its immediate and remote causes and effects. Study of the causes leads back by one route to factors of the environment and by another to anatomical structure and physiological process. Study of the effects leads forward in one direction to behavior, i. e., action in and upon the environment, and in another to bodily changes and processes.

From the biological point of view then every psychic event is a reaction, - a link in the chain, or a moment in the series, of reactions by which the individual adjusts or adapts himself to the environment. The nervous system (or, in the unicellular organisms-if any of their reactions deserve the name psychic, as the writer thinks they do-the body protoplasm and outer membrane) is the specially adapted structure for the performance of the psychic functions or processes. Mind is the abstract name we give ( $I$ ) to the capacity to react in certain, i. e., psychic, ways, (2) to the organized whole of any individual's psychic reactions, or (3) to the content of any individual's psychic reactions, especially ideational ones. It is in reality a function or set of functionsactivity or types of activity-but through misconception it is often used to indicate some mysterious thing which can act of itself or is opposed to or contrasted with body, and it is often referred to as having structure. (See for example, McDougall, 'Mind and Body,' pp. 165, 330.) From a strictly biological point of view it bears the same relation to brain and to the individual that respiration does to lungs and to the individual, or that running does to legs and to the individual. It is the individual, not the brain, that thinks or exercises the other psychic activities we call mind, just as it is the individual, not the lungs, that breathes, or the 
individual that runs, not the legs. But by means of the brain, the lungs and the legs, the individual thinks, breathes, runs.

We do not think of opposing or contrasting respiration or running with lungs, legs or body. Neither should we do so with brain or body in the case of mind. Similarly it is absurd for us to think of respiration as identical with lungs, or running as identical with legs. It is equally absurd to say, as the identificationists still do, that mind is brain, and brain is mind. To speak of a mind-stuff (except in the sense that we may speak of electrical-stuff or light-stuff on the theory that there is no substance but energy, and the writer has never seen it used in this sense) is equally misleading, and savors of the anachronistic notion that mind is secreted by the brain as bile is by the liver-a notion whose absurdity becomes apparent if we again use the comparison of the lungs secreting respiration, or the legs secreting running.

But this view does not mean that we should neglect the brain or nervous system or body, any more than we should in studying respiration or any other function. It is true that we can study many aspects of psychical as well as other functions with only a slight or superficial knowledge of the organs that subserve them. But in physiological psychology some structural knowledge is essential; in comparative psychology the degree of evolutionary development of the nervous system is seen to affect the capacity for psychic reaction; and child psychology is different from adult psychology on account of the individual development, and it is advantageous to have knowledge of these structural conditions. So intimately are structure and function related that it will doubtless be found eventually that racial, family and even individual traits are partly dependent on more or less minute structural differences in brain architecture and nervecell distribution.

In that branch of abnormal psychology which is called psychiatry, in which the scientist has not only to understand the psychological reactions but has to treat the patient also, a knowledge of the brain, nervous system and body in general 
is especially needful. The effect on mental processes of such bodily conditions as fatigue, toxæmias (whether from exogenous or endogenous sources), and brain lesions needs only be mentioned, to have its importance recognized. On the other hand, the effects of certain psychical processes, notably some of the emotions, on bodily activities have recently been emphasized by Crile, Cannon and others. In the writer's belief the affects intermediate between the ideational activities on the one hand and the bodily activities on the other, and this action, while usually and most forcibly exerted in the direction indicated, is nevertheless exerted to some extent in the reverse direction-that is, bodily condition acts to some extent on the ideational processes and content through the affects. This is seen especially in the insane. When we see how some of the reactions belonging to two great functions, as digestion and circulation, may mutually affect each other, it should not be a matter for surprise or wonder that some of the reactions of another great function, mind, should affect and be affected by other bodily reactions or functions. From the biological point of view the relations between body and mind are in principle almost as simple as those between body and any other function. The developmental stage of the structure as to both its phylogeny and its ontogeny and the degree of its integrity will determine the capacity of the individual to react in its racial way.

It was said above that in tracing backward the causes of any psychic event we come eventually to the environment. This as a cause of psychic activity has been too much neglected.

It is the work in life of the biological unit to adjust itself to the environment. This means that the environment, or its various factors, must act upon the unit, and that the latter reacts to it. Any given unit will react to the extent of its capacity for reacting, and this is determined by its structure. The greater the number of environmental factors to which it can react, the more complete and adequate will be its response. It is the nature of the environmental factors that has determined the types of response of which the unit is capable. 
What are the great types of factors and how are they arranged in the environment?

I need not dwell on matter, which we call substance, and the modes of energy which we call light, sound, heat, etc., as such types of factors which are met with in the concrete materials and forces of the world we live in.

But as factors there are also other living creatures, with their behavior, and the content of their psychic processes, their thoughts and feelings, especially in man and the higher animals. Predatory animals and their prey, for example, both have to react to the respective desires and behavior of the other. The content of thinking and emotion in man, whether stored in literature or expressed in speech and action in the presence of the responding human, are large factors to which he must respond. They are outside of him, actually existent in the environment. His own past experiences, including his hopes, ambitions and decisions for his future, are actual former occurrences to which he may react in the present, not only by recollecting them but in many other ways, including the predetermination of many future reactions.

Relations are also objective existences to which we human beings at least react. These are not only spatial and temporal, but of inherence, as of the thing in its kind; genetic, as of offspring to parent; social, as of husband to wife, or individual to community; business, as of debtor and creditor; and innumerable other kinds. There has been evolved, in man at least if not in other animals, a capacity to be more or less sensitive to such environmental factors. We need further study of the mechanisms of our sensitivity and reactivity to them.

Similarly, there is law or necessity as a factor or group of factors. The sword of Damocles must fall if the thread breaks; the walls and roof of the subway must fall in if they are insufficiently shored up; etc. We search for innumerable physical, chemical, genetic and other laws or necessities, and we see them constantly operative in the world about us. It is because they actually exist objectively that there has been evolved in us the capacity for responding to them, not 
only as being subject to them, i. e., compelled to obey them, but as being sensitive to them, comprehending them. Psychology will benefit by a study of them as stimuli as well as of the mechanisms by which we respond to them.

Further, there are obligations and their reverse rights, which are objective existences, at least for us human beings. Whenever two men stand in the relationship of debtor and creditor, there is the obligation of the one to pay, the right of the other to be paid; in the parent-offspring relationship there is the obligation of the parent to protect the offspring till the latter is able to lead its own independent existence, and the right of the offspring to such protection; in the relationship of man and other animals to the respective life activities of others some of us recognize the right of all to live their lives as they please provided they don't interfere with others' rights, some of us recognize such rights only in man, some of us only in white men, some of us only in the dominant white man, or superman, etc., and each of us sees his own obligations according to the limits of his vision. It is the part of ethics to study what those and many other rights and obligations are, of psychology to study the mechanism by which we are sensitive and responsive to them. But psychology cannot adequately study the mechanism without a knowledge of the nature of the stimulus any more than physiology can adequately study the mechanism of digestion without a knowledge of the composition of food-stuffs.

Such, to the writer's mind, are the great types of environmental factors. How are they arranged in the environment?

Every biological unit is not only in an environment, consisting of these factors, but each one is at the center of his own environment, and is himself a part of it. It may be regarded as consisting of a set of concentric circles or spheres, each representing a limited situation, the factors of which act with greater or less force upon the unit at the center, and to which the unit responds with more or less activity, physical and psychical. The limits of the circles are very indefinite, one shading into the other. To illustrate, let us consider a patient in a hospital for the insane. Any con- 
ceivable situation in life would serve, but abnormal conditions sometimes help to illuminate normal ones. What is his environment?

$\mathrm{He}$ is himself at the center of it, his own body, thoughts and feelings being part of it. Next exterior are the room, its walls, windows, doors, the furniture, the warmth, the daylight or lamplight, the people moving about, etc. If the patient is clear, these may be correctly responded to; if he is confused or hallucinated, they may not be. In the next larger circle people speak to him or to each other. He sees books and newspapers about. He may understand what is said or printed, or he may not. Then there are the uniformed women (nurses) and doctors and patients, each having a different relation to each other, the place and to him. He may comprehend these relationships, or may not, in which case he will be puzzled and perplexed. He may recognize the nurse as a nurse, the doctor as a doctor, and be able to call them by name, yet not recognize that he is a patient, that he is in a hospital, etc. He recognizes the terms involved in the relationship, but not the relationship itself. He can see and recognize 2 and 3 but cannot put them together to make 5 .

A wider circle of his situation is that he is sick and in need of care-some of his mental activities are modified, his behavior has been different, he cannot control his thinking or his feeling or his conduct as usual. He may have recognized this and come of his own accord to the hospital, or he may not have recognized it, and others had to bring him against his wish and opposition.

Next, he is a business man and a father of a family. He may realize his obligations to his business associates, customers, creditors, and to his wife and children, or not. They and a host of related conditions form parts of his situation.

He may have done, or think he has done things in the past-such as acquire some venereal disease-which modifies his present condition or thoughts. One can go on to show indefinitely wider spheres of environment.

This illustration is not intended to show the limits of the 
widening circles of environment, for there are no clear-cut ones, but only to indicate that the environment may be regarded in that way. In comparative psychology and in psychiatry we need to know how large is the environment and to what kinds of factors in it the individual we are studying is capable of reacting.

The factors of the inner circles of the environment, the immediate surroundings, mostly concrete, are constantly changing and shifting, requiring constant adjustment on the part of the individual. The remoter ones as a rule change less, somewhat in proportion to their remoteness or abstractness, though not absolutely so. They all have their influence and effect on the conduct of the individual, through the psychological processes involved in his perception and comprehension of the various factors of the whole situation and of their relative importance at the moment of acting. Other psychological activities of course enter into the final behavior or reaction to the environment, such as various affects, plans, decisions, will-impulses, etc.

In psychiatry especially it is necessary to take into account, not only the patient's psychical reactions, but all the bodily conditions that may modify them, and particularly all the environmental factors both immediate and remote, that make up the successive situations in which the patient is and has been. It is in this field that Freud and his followers have taught us so much. It is partly due to that influence that we are realizing more and more that the aim of the psychiatrist should be to study the patient's total reaction to his total environment. The biological point of view makes it insistent however that the study of this total reaction include that of the somatic factors which may modify it, a point that is apt to be somewhat neglected on account of the interest of the psychical reactions. Psychiatry becomes not only a medical science, but an intensive individual psychology as well.

The biological point of view-that every psychic event is a reaction of an individual-if consistently followed and applied, will correct a tendency, prevalent to some extent in 
most if not in all psychologies, very common in James's psychology, and fairly running riot in the writings of the Freudian school, to personify, as it were, or to make independently acting entities of, the psychical functions. For example, Yerkes, ${ }^{1}$ describing an effect of habit, writes that while talking with his friend, ". . . the series of acts gets itself performed ..." Münsterberg ${ }^{2}$ says: "Each man lives in the world which his inner dispositions select and shape." Baldwin, ${ }^{3}$ writing of association, says: ". . a group of processes, ... conspire, so to speak, to 'ring up' one another," and he subsequently speaks of the 'conspiracy' and the 'conspiring elements.' James says: "The psychologist gets to supposing that the thought of an object knows it in the same way that he knows it," and "the thought that thinks it,' and 'thoughts ... know objects,' etc., while Freud notoriously introduces a 'censor' and speaks of libido, of dreams, dream-wishes, and various thoughts, affects and abstractions as though they were endowed with independent initiative and activity. Making all due allowance for a proper use of analogies and of abstractions to avoid descriptive phrases and periphrases, and for literary leavening of an otherwise perhaps heavy dough, there yet remains enough of such usage to indicate a haziness of conception on the part of the writers, and to becloud for the reader a subject not too clear at best-not to mention its scientific inexactitude.

For the same biological point of view the scientifically sterile conception of a 'stream of consciousness,' with the pseudo-problems that it raises, does not exist (except as a fancy), any more than an analogous conception of a "stream of respiration' could exist. In sleep the organism reacts psychically to a slight degree, in unconsciousness it ceases to react at all in those ways, though it continues to react in most physiological ways. The unity of the 'ego' is deter-

1 'Introduction to Psychology,' p. 383.

2 'Psychology, General and Applied,' p. 221.

' 'Mental Development,' p. 266.

- 'Principles of Psychology,' Vol. I., p. 196.

Ibid., p. 197. 
mined by the facts that it is the same organism which reacts at successive times, that each experience is recorded in the same individual (not in any other), and that the organism can recall the content of most of these experiences by subsequent psychical activities. The partial or split personalities -wrongly called multiple personalities-are partly comprehensible on the grounds that the individual, through mechanisms of which we know little, can not recall and make use of large groups or sets of experiences, and can react in more than one way at a time.

This point of view may seem to be a purely mechanical one, and hence fatalistic, leaving no room for choice or freewill. In the sense that every act, physical, physiological or psychical, has its determinants and its effects, that no reaction is haphazard or occurs by chance, this is true. But that it leaves no room for choice is not true. Every individual, from lowest to highest, is always and inevitably in a situation, some of the factors of which are constantly changing more or less. The individual must react to the environment, even if only by inhibiting all external reactions. But there are many possibilities of reaction (more such the higher the individual is in the evolutionary scale), and the individual can, even must, choose which of the possibilities to carry out. The choice itself, the act of choosing, is a part of the reaction to the situation. The choice is but one of the determinants of the act chosen. There is then a compromise between free-will and determinism. The individual must react, but has a measure of choice-freedom of will-as to how it shall react, $i$. e., as to what reaction it shall make.

Thus it may be said that from the biological point of view man is a biological unit reacting to his environment; that his reactions are partly psychical and partly physical or physiological; that every psychical event is a reaction; that the organized whole of the psychic reactions, or the capacity to react in psychical ways, or the content of the psychic reactions is mind, which is related to body as function or activity is related to structure; that to understand fully the psychic reactions it is desirable and in some instances neces- 
sary to know the structure which subserves the function, the modifications of this structure, and the causes which modify it (and hence the function which it subserves); that it is also necessary to know the nature of the various factors of the environment and their grouping in a situation when considering the psychology of any individual's behavior or reaction to the situation; that in psychiatry we must seek to learn the patient's total reaction to his total environment. 